\title{
Rifampicin Induced Acute Interstitial Nephritis And Exfoliative Dermatitis Complicating Pulmonary Tuberculosis - A Case Report
}

\author{
Afroz Fa, Hossain MD ${ }^{\mathrm{b}}$, Ahmed JUc ${ }^{\mathrm{c}}$, Haque $\mathrm{WMM}^{\mathrm{d}}$
}

\begin{abstract}
Rifampicin is one of the most effective antitubercular agents. Among its rare adverse effects, acute interstitial nephritis is noteworthy. Furthermore, exfoliative dermatitis caused by rifampicin is quite uncommon. Simultaneous occurrence of the both complications in the same patient has not been reported so far. Here we describe a case history of a 76-year-old male who developed rifampicin induced acute interstitial nephritis and exfoliative dermatitis at the same time.
\end{abstract}

Key words: Rifampicin, acute interstitial nephritis, tuberculosis.

(BIRDEM Med J 2017; 7(2): 168-171)

\section{Introduction}

Prompt anti-tuberculosis treatment remains the most important and effective intervention for controlling tuberculosis (TB), but adverse events from first-line antitubercular medication are not uncommon. Acute interstitial nephritis is a rare but one of the severe complications that can interrupt treatment amongst patients on anti- tubercular therapy and cause permanent kidney damage. Rifampicin is the most common antitubercular drug responsible for this. Although it typically occurs in patients receiving intermittent rifampicin therapy, cases occurring during continuous treatment have also been reported. ${ }^{1}$ Exfoliative dermatitis caused by rifampicin is also very rare. Most patients recover from these grave conditions upon discontinuation of rifampicin. The aim of reporting this case is to create awareness among our clinicians regarding the rare

\section{Author information}

a. Dr. Farhana Afroz, FCPS (Medicine), Registrar, Internal Medicine, Ibrahim Medical College and BIRDEM, Dhaka.

b. Dr. Md. Delwar Hossain, MD (Chest), Associate Professor, Internal Medicine, Ibrahim Medical College and BIRDEM, Dhaka

c. Dr. Jamal Uddin Ahmed, FCPS (Medicine), Assistant Professor, Internal Medicine, Ibrahim Medical College and BIRDEM, Dhaka

d. Dr. Wasim Md. Mohosinul Haque, FCPS (Medicine), Associate Professor, Nephrology and Dialysis, BIRDEM, Dhaka.

Address of the correspondence: Dr. Farhana Afroz, Registrar (Medicine), Ibrahim Medical College and BIRDEM, Shahbag, Dhaka-1000, Bangladesh. Email: lubna0408@gmail.com

Received: October 28, $2016 \quad$ Accepted: February 28, 2017 adverse effect of rifampicin which if detected earliar, can be completely reversible.

\section{Case Report}

A 76-year-old male with diabetes, hypertension and chronic kidney disease (CKD) stage-3 presented with fever and cough for 4 weeks and was diagnosed as smear positive pulmonary tuberculosis (AFB++).

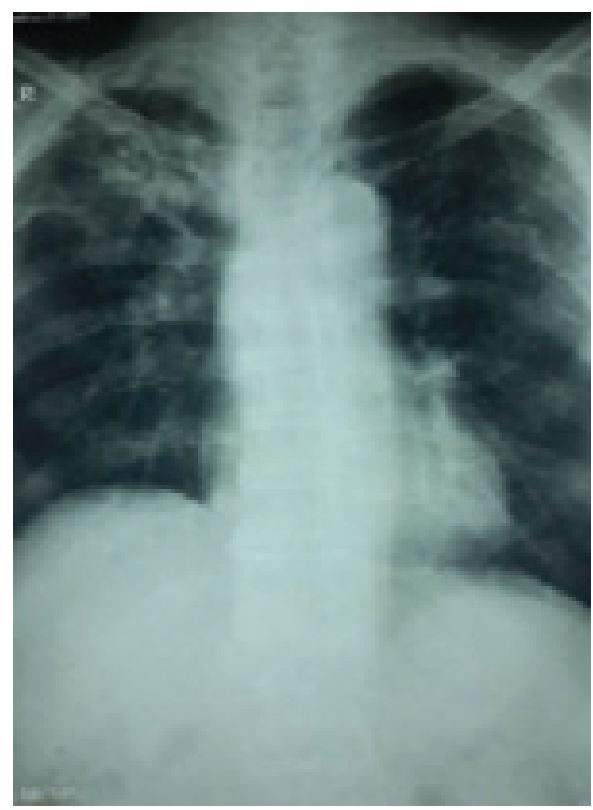

Figure 1. Chest $X$-ray posterior-anterior view showing inhomogeneous opacity in right upper zone 


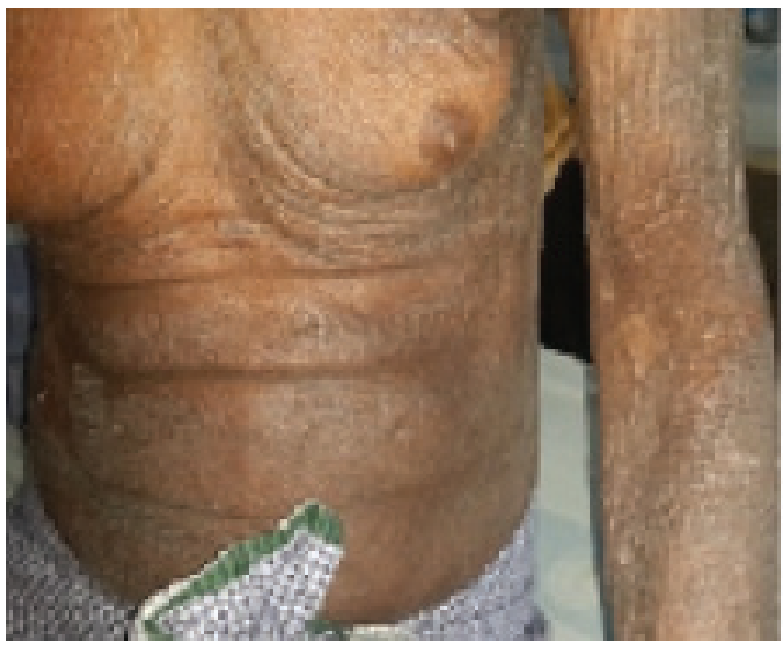

(a)

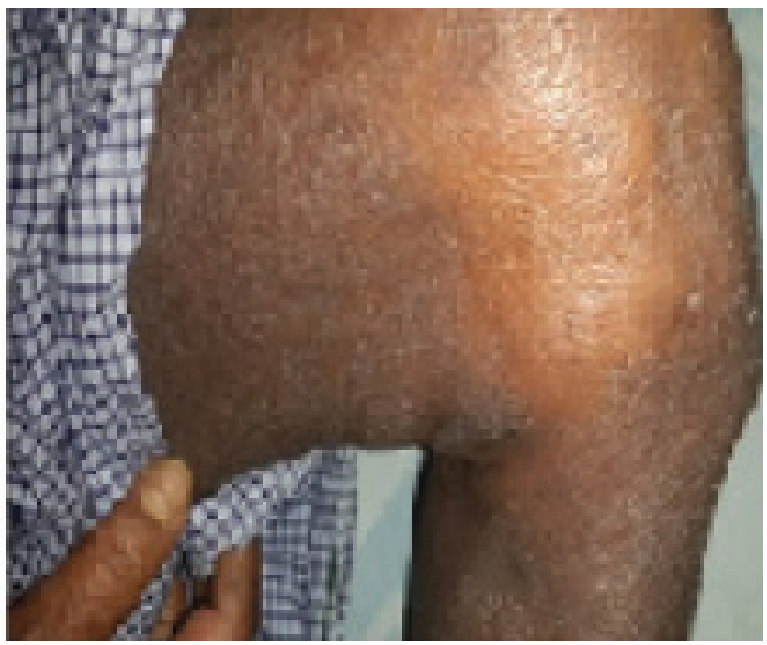

(b)

Figure 2 (a \& b). Exfoliative Dermatitis involving trunk and limb.

Modified anti-tubercular regime for CKD was started as per guidelines. After 5 weeks, he developed generalized pruritus with exfoliation and serum creatinine was raised from his baseline of $2 \mathrm{mg} / \mathrm{dl}$ to $3.0 \mathrm{mg} / \mathrm{dl}$.

Anti-tubercular drug induced hypersensivity reaction with acute kidney injury (AKI) on CKD was suspected and all anti-tubercular drugs were stopped.No other cause of AKI was found. There was oliguria and his vitals were within normal limit. We treated him with oral $(1 \mathrm{mg} /$ $\mathrm{kg}$ ) and topical steroid, hydroxyzine hydrochloride and liquid paraffin. In next 2 weeks the lesions gradually improved and serum creatinine began to fall $(2.2 \mathrm{mg} /$ dl).

As he was smear positive (sputum $\mathrm{AFB}++$, sputum for Gene Xpert: MTB detected [Rif sensitive] sputum C/S: No growth), we planned to restart anti-tubercular medication sequentially at low dose and gradually reach to full dose and find out the culprit drug. But administration of rifampicin resulted in reappearance of symptoms (pruritus and erythema) within 48 hours and serum creatinine began to rise again. So, rifampicin was stopped immediately.

Further diagnostic workup revealed the following-

\begin{tabular}{|c|c|c|}
\hline Investigation & Patient's Valve & Referecne vlaue \\
\hline$\overline{\mathrm{CBC}}$ & $\begin{array}{ll}\text { - } & \mathrm{Hb}-10.8 \mathrm{gm} / \mathrm{dl} \\
\text { - } & \mathrm{TCWBC}-12,120 / \mathrm{cmm} \\
\text { - } & \mathrm{DC}(\mathrm{N}-73.8 \%, \mathrm{~L}-13.9 \%, \mathrm{M}-6.1 \% \\
& \mathrm{E}-25 \% \text { (previous E-8.2\%) } \\
\text { - } & \text { Pc-165,000/cmm } \\
\text { - } & \text { ESR-58 mm in } 1 \text { hour }\end{array}$ & $\begin{array}{l}\text { - } \mathrm{Hb}(13-18 \mathrm{mg} / \mathrm{dl}) \\
\text { - } \mathrm{TC} \mathrm{WNC}-4000 \text { to } 11,000 / \mathrm{cmm} \\
\text { - } \mathrm{Dc}(\mathrm{N}-45-70 \%, 1-20-40 \%, \\
\mathrm{m}-2-10 \%, \mathrm{e}-1-6 \%) \\
\text { - } \mathrm{PC}-150,000-400,000 / \mathrm{cmm} \\
\text { - } \mathrm{ESR}-0-10 \mathrm{~mm} \text { in } 1^{\text {st }} \text { hour }\end{array}$ \\
\hline PBF & Normocytic Normochromic Anemia & \\
\hline Urine for Routine Eamination & $\begin{array}{l}\text { - Albumin 2+ aectone: Nil } \\
\text { - Pus cell: } 8-10 / \mathrm{HPF} \\
\text { - } \text { RBC: Nil } \\
\text { - While cell and Granular cast present }\end{array}$ & Absent in healthy subject \\
\hline Urinary total protein & $2.05 \mathrm{mg} /$ day & Less than $1 \mathrm{gm} /$ day \\
\hline Urine culture \& sensitivity & No growth of organism & \\
\hline
\end{tabular}


Other investigation revealed - Serum electrolytes: normal. Ca- corrected- $8.9 \mathrm{mg} / \mathrm{dl}$; PO4- $3.5 \mathrm{mg} / \mathrm{dl} \mathrm{STP-}$ 49.9 and Albumin- $23.5 \mathrm{gm} / \mathrm{dl}$; AST- $15 \mathrm{U} / \mathrm{L}$ ALT- 26 U/L; ALP- 70 U/L; Billirubin- 0.4 mg/dl. Antinuclear antibodies were negative and $\mathrm{C} 3$ and $\mathrm{C} 4$ levels were normal. He had hyperuricemia with an uric acid level of $9.0 \mathrm{mg} / \mathrm{dl}$ that was treated with Febuxostat (40 mg daily). Sputum for AFB culture was also sent.

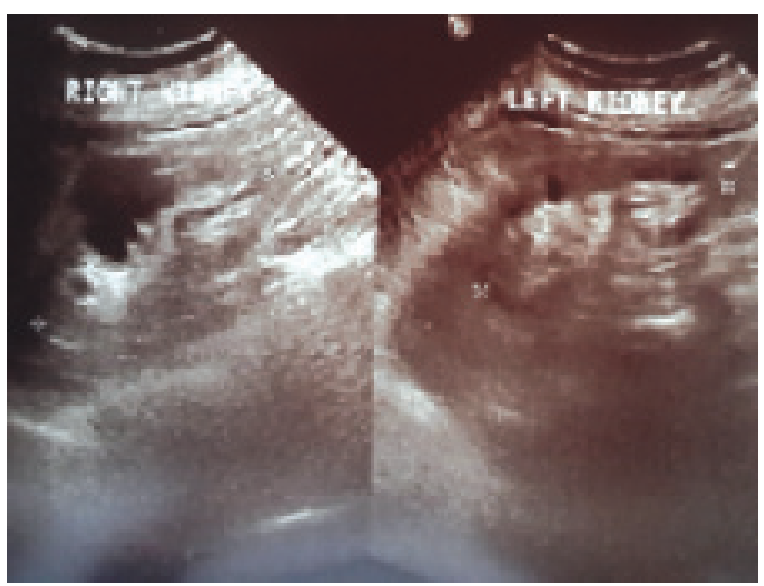

Figure 3. Ultrasonogram of whole abdomen showed bilateral renal parenchymal disease

At this point we had a plan to do renal biopsy but unfortunately it could not be done due to small kidney (Lt-8.0 cm, Rt-7.8 cm).

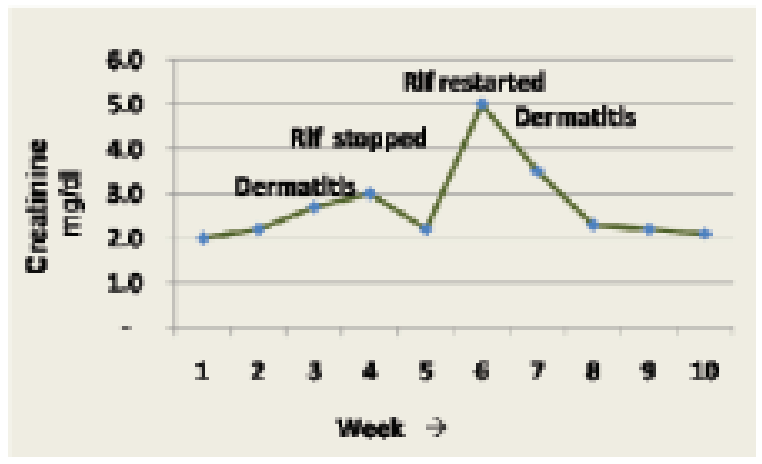

Figure 4. Temporal relation between introduction of rifampicin with serum creatinine and appearance of skin rash

Finally, his skin condition and renal function began to improve upon discontinuation of rifampicin and serum creatinine returned to previous value after 2 weeks of stopping the drug. The anti-tubercular medication was tailored by omitting rifampicin and adding moxifloxacin and duration of treatment was extended. On subsequent follow-up visit he was finally declared as "cured".

\section{Discussion}

Despite being uncommon, rifampicin is the most frequent anti-tuberculous medication associated with acute interstitial nephritis. ${ }^{2}$ Adverse reactions associated with rifampicin usually occur in patients who have either previously taken the drug or received intermittent treatment. ${ }^{3}$ Our patient had no history of taking rifampicin previously.

In a retrospective study done between the years 1995 and 2007, 41 patients had a confirmed diagnosis of acute interstitial nephritis. All patients received an intermittent regimen of anti-tuberculous therapy containing rifampicin. This association of intermittent or previous exposure is hypothesized to be related to rifampicin's ability to produce an immune response, which eventually leads to cell destruction.

Acute interstitial nephritis should be suspected in a patient who presents with an elevated serum creatinine and a urinalysis that shows white cells, white cell casts, and in some cases, eosinophiluria. ${ }^{4}$ Although a definitive diagnosis of acute interstitial nephritis should be made by renal biopsy, it may not be necessary in patients who have clearly documented onset of renal failure after initiation of a culprit drug and improve immediately upon stopping the offending agent. ${ }^{5,6}$ In our patient renal biopsy could not be done due to small kidneys and he improved satisfactorily upon discontinuation of rifampicin. Furthermore, acute renal injury related to rifampicin is usually a clinical diagnosis. Most reports or series did not include a pathological diagnosis. Beck and Salant noted that when renal failure occurs in the setting of exposure to an offending agent, biopsy is generally not required for diagnosis. ${ }^{7}$ When biopsy is performed, the most common findings are acute interstitial nephritis or acute tubular necrosis.Schubert's series from South Africa included only patients with biopsy-proven acute interstitial nephritis who were on chemotherapy for tuberculosis. In this study of 41 patients, acute interstitial infiltrate was present in all cases but acute tubular necrosis was also noted in $90 \%{ }^{8}$ Other less common pathological associations noted with rifampin induced kidney disease includes diffuse proliferative crescentic glomerulonephritis. 
Although controversial, there is some evidence suggesting that corticosteroid therapy accelerates renal recovery in patients diagnosed with drug-induced interstitial nephritis. A retrospective study examined 61 patients with biopsy-proven drug-induced acute interstitial nephritis. The study concluded that there was a correlation between the delay in the onset of steroid treatment and final serum creatinine level. Conversely, in another study of 42 patients with acute interstitial nephritis, 26 were given steroid therapy while 16 were not treated. ${ }^{9}$ The study revealed no significant difference in serum creatinine levels between the two groups after one, six, and twelve months of follow up.

Exfoliative dermatitis caused by rifampicin is also very rare. ${ }^{10}$ It is one of the presentation of Cutaneous adverse drug reactions (CADR). In a large tertiary care centre study on CADR with antitubercular drugs, pyrazinamide was the commonest offending drug (2.38\%), followed by streptomycin (1.45\%), ethambutol (1.44\%), rifampicin $(1.23 \%)$ and isoniazid $(0.98 \%)$. Majority of cutaneous hypersensivity reactions occurred within two months after the initial dose ${ }^{\mathbf{1 1}}$.In our case, patient developed exfoliative dermatitis by end of $5^{\text {th }}$ week of treatment and was improved with prompt withdrawal of the offending agent and institution of steroids.

\section{Conclusion}

Rifampicin associated exfoliative dermatitis and acute interstitial nephritis should be kept in mind while treating patients with tuberculosis who develop skin lesions and deterioration of renal function respectively. High index of suspicion is needed for early diagnosis and recovery by discontinuation of rifampicin.

\section{Conflict of interest: None}

Declaration: This paper was presented in the 33rd World Congress of Internal Medicine, Bali, Indonesia, 2016.

\section{References}

1. Aminiafshar S, Alimagham M, Abbasi F, Fard-Khani SK. Acute interstitial nephritis associated with rifampicin therapy. Saudi J Kidney Dis Transl 2009; 20:1079-80.

2. M.R. Clarkson, L. Giblin, F.P. O'Connell, P. O'Kelly, J.J. Walshe, P. Conlon, et al. Acute interstitial nephritis: clinical features and response to corticosteroid therapy. Nephrol Dial Transplant 2004; 19 (11): 2778-83.

3. T. Muthukumar, M. Jayakumar, E.M. Fernando, M.A. Muthusethupathi. Acute renal failure due to rifampicin: a study of 25 patients. Am J Kidney Dis 2002; 40 (4) :690-96.

4. De Vriese AS, Robbrecht DL, Vanholder RC, Vogelaers DP, Lameire NH. Rifampicin-associated acute renal failure: pathophysiologic, immunologic, and clinical features. Am J Kidney Dis 1998; 31:108-15.

5. Micheal DM,Kelly CJ. Acute interstitial nephritis J Am Soc Nephrol 1998; 9:50.

6. V.V. Rekha, T. Santha, M.S. Jawahar. Rifampicin-induced renal toxicity during retreatment of patients with pulmonary tuberculosis. J Assoc Physicians India 2005; 53: 811-13.

7. Beck L.H. Salan D.J. Tubulointerstitial diseases of the kidney. In:Kasper,Fauci,Hauser,Longo,Jameson,Loscalzo eds. Harrison's Principles of Internal Medicine. $18^{\text {th }}$ ed. McGrawHill Professional Publishing 2012; United states of America: pp 2367-74.

8. C. Schubert, W.D. Bates, M.R. Moosa. Acute tubulointerstitial nephritis related to antituberculous drug therapy. Clin Nephrol 2010; 73 (6): 413-19

9. Acute interstitial nephritis: clinical features and response to corticosteroid therapy. Nephrol Dial Transplant 2004; 19 (11): 2778-83.

10. Goldin HM, Schweitzer WJ, Bronson DM. Rifampin and exfoliative dermatitis. Ann Intern Med 1987; 107(5):78.

11. Ruchi Dua, Girish Sindhwani,Jagdish Rawat. Exfoliative DermatitisTo All Four First Line Oral Anti-Tubercular Drugs. Indian J Tuberc 2010; 57: 53-56 